\title{
A Temperamental Approach in Promotion of Health
}

\author{
Malik Itrat ${ }^{1^{*}}$ and Mohd Zulkifle ${ }^{2}$
}

${ }^{1}$ Department of Tahaffuzi wa samaji Tib, National Institute of Unani Medicine, Bangalore

${ }^{2}$ Department of Kulliyat, National Institute of Unani Medicine, Bangalore

"Corresponding author: Malik Itrat, Department of Tahaffuzi wa samaji Tib, National Institute of Unani Medicine, Bangalore, Karnataka 560091, India, Tel: 917411602926; Email: malik.itrat@gmail.com

Rec date: Feb 07, 2014; Acc date: July 25, 2014; Pub date: July 27, 2014

Copyright: (c) 2014 Itrat and Zulkifle. This is an open-access article distributed under the terms of the Creative Commons Attribution License, which permits unrestricted use, distribution, and reproduction in any medium, provided the original author and source are credited.

\begin{abstract}
The Unani system of medicine is a comprehensive medical system, which meticulously deals with the states of health and disease. Its holistic approach considers individual in relation to his environment and stresses on health of body, mind and soul. Temperament of a person is given great importance for identifying the most suitable diet and lifestyle for promoting the health of a particular individual. On the basis of Mizaj human beings have been categorized into four qualitative types: Damvi (sanguinous), Safravi (bilious), Balghami (phlegmatic), Saudavi (melancholic). They were supposed to result from predominant humor in the body. Any change in the temperament of person brings about change in person's state of health. There are some factors like age, place, season, diet and occupation, which are responsible for influencing the temperament of an individual and predispose them to a particular group of diseases similar to the temperament of that individual. Thus, the person of specific temperament becomes prone to a particular group of diseases in different phases of their life and under different climatic conditions. In Unani medicine, different guidelines for different temperaments have been mentioned for promotion and preservation of health. Thus, in this paper authors have highlighted the importance of temperamental approach for the promotion of health and prevention of diseases.
\end{abstract}

\section{Key Words:}

Mizaj; Temperament; Unani medicine; Health promotion

\section{Introduction}

Health promotion is the process of enabling people to increase control over and to improve health. It is not directed against any particular disease but is intended to strengthen the host through a variety of approaches or interventions. The well-known interventions in this area are health education, environmental modification, life style and behavioural changes. The best possible ways of health promotion in Unani system of medicine is maintenance of balanced temperament. This system of medicine is a comprehensive medical system, which meticulously deals with the states of health and disease. The unique holistic approach of Unani medicine is its fundamental principles. The principles related to human biology are seven natural factors that make up the totality of a human being, viz. Arkan (Elements), Mizaj (Temperament), Akhlat (Humours), Aaza (organs), Arwah (Pneuma), Quwa (Faculties) and Afa'l (Functions). Among these principles, most important is mizaj (Temperament). The meaning of the word temperament according to Taber's dictionary is "The combination of intellectual, emotional, ethical and physical characteristics of a specific individual". While in Unani concept, Mizaj is the quality produced by the action and reaction of opposite qualities of building components. When these components interact by virtue of their respective qualities, a condition is achieved which is found in equal proportion in all the components of the compound this is called mizaj. It represents the physical and chemical properties of the body. Thus Mizaj can be described as the resultant quality that comes out of interaction amongst the constituents of a compound. Literal meaning of word mizaj is intermixing [1,2].Temperament of a person is given great importance for identifying the most suitable diet and lifestyle for promoting the health of a particular individual. According to Hippocrates, it is more important to know what sort of a person has a disease rather than to know what sort of a disease person has. On the basis of Mizaj human beings have been categorized into four qualitative types: sanguinous (Damvi), bilious (Safravi), phlegmatic (Balghami), melancholic (Saudawi). They were supposed to result from predominant humor in the body [3]. Temperament of the body is specific for each individual fluctuating between certain minimum and maximum limits. Any change in the temperament of person brings about change in person's state of health [4,5]. Therefore maintenance of balanced temperament under the varying conditions of life is necessary for the preservation of health and avoidance of disease in an individual. There are some factors like age, place, season, diet and occupation having their specific temperament, responsible for influencing the temperament of an individual and predispose them to a particular group of diseases. Thus, the people of specific temperament become prone to a particular group of diseases in different phases of their life and under different climatic conditions [4,5]. If a person of safravi Mizaj adopts har-yabis tadabeer, then he becomes prone to develop diseases similar to the temperament of that individual like acute fevers, heat-stroke, dehydration, hypertension, insomnia, indigestion etc. Similarly, a person of balghami mizaj gets barid tadabeer; he will be more susceptible to develop diseases like hummae balghami, obesity, nervine diseases, female infertility, asthma $[4,6]$ etc. So, it is necessary to be acquainted with those factors responsible for change in temperament of human beings and regimens to minimize the impact of these factors on the temperament.

\section{Damvi Mizaj (Sanguine temperament)}

Identification 


\section{Signs of the dominancy of blood (Ghalbae dam)}

\section{Regimens}

In order to remain healthy, they should adopt the following lifestyle factors:

A) Avoid staying for long in hot and moist air. They can tolerate cold easily.

B) Winter is the best season for damvi mizaj persons.

C) They should preferably drink cold water and avoid excessive sugar, rich fatty foods and meat consumption.

E) They should use barid-yabis foods.

F) Exercise should be so gentle that there is no over production of heat in the body.

G) Eliminative measures such as venesection and purgation should be carried out early in spring.

H) They should gargle with decoction of Mastagi, Habbul aas, and Aaqirqarha for the evacuation of morbid matter present in the brain.

I) Damvi mizaj persons are more susceptible to infectious diseases. So, they should use such drugs which have dafe taffun action.

J) Excessive excitement, worry, anger or emotional excesses should be avoided [9].

\section{Safravi Mizaj (Choleric temperament)}

\section{Identification}

This temperament is marked by a medium stature, sharp angular features, medium/lean built, yellowish complexion, brilliant penetrating eyes, prominent veins and hairy body. Hairs are black, abundant, thick and curly. Pulse is rapid and strong. They feel comfort with cold things and get trouble with hot things. Most suitable season for them is winter. They have good digestion, sharp and quick appetite and sleep is light. They are energetic, bold, daring, and have brilliant intellect but they are impatient, irritable, and short tempered. Often they turned into fearless and rebellious leaders. They have strong inclination to indulge in sexual pleasure. They are indefatigable in their enterprises and most persistent, zealous, passionate and revengeful $[7,9]$.

\section{Signs of the dominancy of bile (Ghalbae safra)}

Yellow colour of eyes and complexion, bitter taste in mouth, rough and dry tongue, excessive thirst, rapid pulse, lack of appetite, nausea with bilious vomiting of green or yellow colour, irritative diarrohea, frequent attacks of tingling in the skin, feeling of burning and irritation as from hot bath or exposure to sun are signs of predominancy of bile. Characteristics dreams of bile are seeing fire and flags of yellow colour. Dominancy of safra predisposes them to diseases like Hummae ghib, T.B., Sudae safravi, Urticaria, Hyperacidity, Erysipelas, Headache, Eyestrain, Hypertension, Stress, and Cardiovascular disorders $[3,7,8]$.

\section{Regimens}

A) Exposure to sun or hot climate should be avoided.
B) They should live in a cool, fresh and properly ventilated environment.

C) Winter season is beneficial for these persons, while they get trouble in summer, because bile increases in this season. So, Mukhrije and Mushile safra drugs should be used by these persons in summer like sikanjabeen, tamarhindi, Aalubukhara, Gule neelofar, Gule banafsha etc.

D) They should use barley water during summer season.

E) Massage with Roghan banafsha should be done in these persons.

F) Persons of safravi mizaj should avoid hammam.

G) They should take meals three times a day.

H) They should avoid salty, fatty and fried foods and Ratab foods should be used by these persons like Cucumber, Water melon etc

I) They should avoid excessive movement and strenuous exercise, time of exercise should be early in the morning or late in the evening.

J) A good night sleep is essential for such type of temperament.

K) Extreme emotions of anger, irritability, excessive talkativeness, and suppression of anger are emotional extremes for this kind of temperament.

L) Bile should be eliminated with emesis, purgation or both according to individual disposition. For purgation, banafsha, tamarind, halela zard should be given $[9,10]$.

\section{Balghami Mizaj (Phlegmatic temperament)}

\section{Identification}

Individuals of this temperament are flaccid, obese with soft and flabby muscles, White complexion, thin and soft hairs. Blood vessels are not prominent and pulse is slow and infrequent. Their movements and activities are sluggish. They feel comfort with hot things and in hot weather. They have round face with full cheeks, large moist eyes, have medium to large frame, more fatty tissue than muscular tissue and bones are well covered. They are calm, have sentimental subjective thinking, emotional, sensitive, tends to be religious, their mind is foggy, and slow. They are sexually frigid and do not get angry easily. Their digestive organs are weak and slow, hence they have less appetite and poor thirst. They are lethargic, dull and take excess sleep. Their memory is poor and power of perception is slow and feeble $[8,11]$.

\section{Signs of the dominancy of phlegm (Ghalbae balgham)}

Flabbiness of body, cold and moist skin, excessive salivation and viscid saliva, excessive sleepiness, mental dullness, soft and slow pulse, weak digestion, pale urine and dreams about water, ice, rain denotes excess of phlegm. Dominancy of phlegm predisposes them to diseases like Common cold, Ascites, Oedema, Hummae balghami, Pneumonia, Asthma, Paralysis, Obesity, Sarsame balghami etc $[4,12]$.

\section{Regimens}

A) Cold air negatively affects them hence air conditioners and cold and wet environment should be avoided.

B) They should use hot and dry foods and avoid cold foods. 
C) Lack of exercise and unnecessary rest during day time especially one hour before sunset should be avoided. They should indulge in strenuous exercise for longer duration. Aerobics is beneficial for them.

D) They should get up early in the morning and avoid sleep after sunrise.

E) Sweating is beneficial, it should never be suppressed and laxatives are also beneficial $[1,2,7,13]$.

\section{Saudavi Mizaj (Melancholic temperament)}

\section{Identification}

\section{Signs of the dominancy of Sauda (Ghalbae sauda)}

Dry and dark skins, anxiety, burning in epigastrium, false appetite, thick and turbid urine, dreams is usully full of anxiety and are often of dark places and fearful objects. Excess of sauda predisposes them to diseases like Leprosy, Hummae ruba, Splenomegaly, Constipation, Anorexia, Arthritis, Neuromuscular and Psychiatric disorders $[3,9,10]$.

\section{Regimens}

A) Ibne Rushd has advocated Dalak layyan, mild exercise, long sleep, and har-ratab foods for these persons.

B) They should avoid staying in cold and dry environmental conditions for long. They need to be protected in dry weather conditions. Seashore and coastal areas are beneficial for their health.

C) Melancholic should avoid old, dry and stale food, excessive beans, nuts, astringent foods, peanuts, tomatoes, brinjal and rancid fats are harmful for them even in small quantities.

D) Tea, coffee and artificially flavored drinks should be avoided.

E) Har-Ratab foods should be given to these persons like anjeer, maveez, Chana, lobiya, apple, anar shirin, turnip, ginger etc.

F) Moderate and light exercise for short durations is best suited for such temperaments; especially walk for 15 minutes after dinner.

G) They should go to bed early for 6-8 hours night sleep. They are more prone to insomnia.

H) Feeling of loneliness, depression and grief can have much more negative influence especially if prolonged or excessive.
I) They should drink at least 2-3 litres of water daily.

J) Bodily wastes like urine and stool should never be suppressed.

K) Sauda should be evacuated from the body. For this purpose haleelajat and bisfaij should be used [7-10].

\section{Conclusion}

People of one type of temperament are prone to a particular group of diseases in different phases of their life and under different climatic conditions due to dominance of particular humor in particular temperament. This susceptibility can be checked by adopting the temperament specific regimens given by Unani physicians. Hence, temperament based preventive approach of Unani medicine can offer a better way for promotion and preservation of health with least cost

\section{References}

1. Gruner O, Cameron A (1929) Treatise on the Canon of Medicine. Burleigh Press London 57-75.

2. Shah H, Mazhar (2007) The Canon of Medicine. Idara Kitabus Shifa New Delhi 336-337.

3. Kabeeruddin M, Kulliyate qanoon (2006) Eijaz Publishin House New Delhi 239-240.

4. Zaidi IH, Zulkifle M, Ahmad SN (1999) Temperamentology. Aligarh: competent Xerox centre 12-24

5. Azmi AA (1972) Basic Concepts of Unani medicine- A critical study. New Delhi IHMMR

6. Ansari AH, Zulkifle M, Ali Mahboob (2010) An analytical study of Concordance between mizaj and diseases in adult patients of NIUM Hospital Bangalore. Ancient Science of Life 30 :7-11

7. Zakariya Razi, Kitabul mansuri (1991) CCRUM New delhi 59-64.

8. Ibne Sina, Alqanoon Fil Tib (2010) Idara Kitabus Shifa New Delhi 26-32.

9. Ibne rushd (1980) Kitabul kulliyat. CCRUM New delhi 82-92, 158-60, 352-54.

10. Arzani akbar, Ikseer-al-quloob (2010) CCRUM New delhi 3-24

11. Majusi Al Abbas. Kamilus sanaah (2010) Idara Kitabus Shifa (1st edn) New Delhi 25-31.

12. Jurjani Ismail, Zakheera Khwarzam Shahi (2010) 1st (edn) Idara Kitabus Shifa New Delhi 17-21

13. Ibne hubl Baghdadi (2005) Kitabul mukhtarat. Ccrum New delhi: 23-26, 262-63

14. Arzani Akbar, Mufarreh al quloob (2002) Idara Kitabus Shifa. New Delhi 19-33 